\title{
The Prenatal High Risk Factors in Non-Syndromic Cleft Lip or/and Palate Fetuses: A Cohort Study Based on Maternal Health Care Records of a Population
}

\author{
Bing Li ${ }^{1, \#}$, Xiao-Hua Xiao ${ }^{2, \#}$, Ang Chen ${ }^{3}$, Ying Li ${ }^{1}$, Hui-Fang Lin¹, Hua-zhao Lin ${ }^{1}$, and Feng-Hua Liu,* \\ ${ }^{1}$ Department of Health Education, Guangdong Women and Children Hospital, Guangdong, China \\ ${ }^{2}$ Department of Dean, Boai Hospital of Zhongshan Affiliated to Southern Medical University, Guangdong, China \\ ${ }^{3}$ Department of Science and Education, Boai Hospital of Zhongshan Affiliated to Southern Medical University, Guangdong, China \\ ${ }^{4}$ Department of Reproductive Health and Infertility, Guangdong Women and Children Hospital, Guangdong, China \\ "Equally contributed
}

*Corresponding authors: Professor. Feng-Hua Liu, Department of Reproductive Health and Infertility, Guangdong Women and Children Hospital, No. 521, Xingnan Road, Guangzhou 511442, Guangdong, China, E-mail: liushine2006@163.com

Received: 11 Jul, 2021 | Accepted: 24 Jul, 2021 | Published: 31 Jul, 2021

Citation: Li B, Xiao XH, Chen A, Li A, Lin HF, et al. (2021) The Prenatal High Risk Factors in Non-Syndromic Cleft Lip or/and Palate Fetuses: A Cohort Study Based on Maternal Health Care Records of a Population. J Clin Case Stu 6(3): dx.doi.org/10.16966/2471-4925.229

Copyright: (C) $2021 \mathrm{Li} \mathrm{B}$, et al. This is an open-access article distributed under the terms of the Creative Commons Attribution License, which permits unrestricted use, distribution, and reproduction in any medium, provided the original author and source are credited.

\section{Abstract}

Background/Aim: To determine the associations of different prenatal factors with the development of non-syndromic cleft lip or/and palate (NSCL/P), as there are still no consensus to the risk factors of NSCL/P.

Methods: Nested case-control study based on the gestational period health care record data of all singleton NSCL/P ( $n=197$ ) and fetuses without birth defects ( $n=192706)$ born in-hospital of Zhongshan between 2016 and 2019.

Results: Vagina infected (OR 3.43,95\% Cl 1.34-7.19), assisted conception (OR 11.57, 95\% Cl 0.65-54.29), folic acid intake <3 months during pre- and early pregnancy (OR 1.57, 95\% Cl 1.10-2.30), incomplete placenta or rough surface placenta (OR 4.65, 95\% Cl 3.23-6.57), abnormal amniotic fluid (OR 2.74, 95\% Cl 2.04, 3.67), low birth weight of newborns (OR 5.44, 95\% $\mathrm{Cl} 3.41-8.54$ ), preterm delivery (OR 3.29, 95\% $\mathrm{Cl} 2.07-5.24$ ), and post-term delivery (OR 5.94, 95\% $\mathrm{Cl} 0.97-18.93$ ) were associated with a higher risk of NSCL/P.

Conclusions: The status of placenta and fluid were discovered as risk factors with NSCL/P, which strengthens the importance role of interaction between the placental barrier and various environmental factors on the development of NSCL/P.

Keywords: Cleft lip or/and palate; Prenatal risk factors; Maternal health care records; Cohort study

Abbreviations: NSCL/P: Non-Syndromic Cleft Lip or/and Palate; CL/P: Cleft Lip or/and Palate; BMI: Body Mass Index; HBsAg: Hepatitis B Surface Antigen; G6PD: Glucose-6-Phosphate Dehydrogenase Deficiency; MLRM: Multiple Logistic Regression Model; VIF: Variance Expansion Factor; Cls: Confidence Intervals

\section{Introduction}

Cleft lip or/and palate $(\mathrm{CL} / \mathrm{P})$ are most common serial congenital anomalies to affect the orofacial region, and the overall incidence of CL/P is approximately 1 in every 700 to 1000 births with wide variation across geographic areas, ethnic group and nature of cleft itself [1-3]. CL/P occurs between the $6^{\text {th }}$ and $12^{\text {th }}$ week of pregnancy during early embryologic development, and has complex etiology thought to involve genetic influences with variable interactions from environmental factors [4-6].

Non-syndromic cleft lip or/and palate (NSCL/P) accounts for $70 \%$ of $\mathrm{CL} / \mathrm{P}$ cases, and it is isolated anomaly without other congenital anomalies. Several previous studies have reported more than 30 genetic risk loci that are responsible for pathogenesis of NSCL/P, but the major cause of NSCL/P has not been fully elucidated due to complex interaction between genetic and environmental risk factors $[7,8]$. Meanwhile, the reported environmental factors associates with $\mathrm{NSCL} / \mathrm{P}$ are variational in different studies, and there was few study focus on prenatal factors of NSCL/P. However, the prenatal physiologic and pathological changes reflect the effects of environmental factors on fetuses, further large sample sizes study on prenatal factors of $\mathrm{NSCL} / \mathrm{P}$ is needed.

The aim of this study was to determine the associations of different prenatal factors with the development of NSCL/P. The gestational period health care record data of 192903 fetuses born between 2016 and 2019 in one city region were used to explore the prenatal risk factors on NSCL/P. 


\section{Methods}

\section{Study design and participants}

This nested case-control study included 192903 singleton fetuses were born (included artificial termination of death pregnancy) inhospital from January 1, 2016 to December 31, 2019 in Zhongshan City of China. We extracted the maternal health care record data of total 204119 pregnant women and their 206850 fetuses from the regional information system databases of maternal and children health care of Zhongshan during this period, and all the private identity information was excluded when we extracted the data. All the target fetuses delivered between 2016 and 2019, we excluded 5446 twins and multiple pregnancies, 23 singleton fetuses with syndromic cleft lip or/and palate (SCL/P), and 8478 singleton fetuses with other birth defects (no cleft lip or/and palate), and then there were 192903 singleton fetuses were included in the final pregnancy cohort. In the final cohort, the cases were 197 singleton fetuses with non-syndromic cleft lip or/and palate (NSCL/P), the controls were 192706 singleton fetuses without NSCL/P and without other birth defects.

We confirm that all methods were carried out in accordance with relevant guidelines and regulations of ethical review of biomedical research involving human beings issued by Health and Family Planning Commission of the People's Republic of China in 2016. This study used the de-identified historical health record data belong to information centre of health bureau of Zhongshan city, and informed consent was waived by the ethical review board of Guangdong Women and Children Hospital.

From the real records data, we got these variables in prenatal period as candidate risk factors, included mother's age, education level, job, per capita household income, pre-pregnancy body mass index (BMI), folic acid intake during pre- and early pregnancy, risk factors exposure in early pregnancy, illness history, assisted conception, prenatal Down's screening, liver function test, renal function test, urine occult blood, hepatitis B surface antigen ( $\mathrm{HBsAg}$ ), syphilis test, scarred uterus, gestational diabetes mellitus, hypertensive disorder, thalassemia carrier, anemia, thyroid dysfunction or abnormalities, vagina infected, glucose-6-phosphate dehydrogenase deficiency (G6PD), incomplete placenta, placental roughness, torsion of umbilical cord, umbilical cord around neck, amniotic fluid abnormal, fetal position, and gender of newborns.

\section{Statistical analysis}

The data were analysed using R version 3.6 .2 (2019-12-12). Firstly, all variables were tested by $\chi^{2}$ tests. Secondly, all variables were used to set-up a multiple logistic regression model (MLRM), and variance expansion factor (VIF) scores were calculated to verify the multicollinearity of independent variables. The variables of illness history and HBsAg were excluded from the MLRM for their VIF scores $>10$, and a new MLRM was set-up. And then a final simple MLRM was set-up using the variables with the $p$ value $<0.05$ in the new MLRM, the ORs and their 95\% confidence intervals (CIs) of these variables were calculated. The missing values of variables were recoded to unknown for analysis. In all analyses, $p$ values $<0.05$ were considered significant

\section{Results}

\section{General characters}

In all 192903 fetuses, there were 197 (0.10\%) non-syndromic cleft lip or/and palate (NSCL/P), among them, there were $74(37.56 \%)$ cleft lips without palates, $43(21.83 \%)$ cleft palates without lips, and 80
(40.61\%) cleft lips with palates. The prenatal general characteristics of all fetuses and their mothers are given in table 1. By $\chi^{2}$ tests, it showed education of mothers, pre-pregnancy BMI grades of mothers, and folic acid intake during pre- and early pregnancy might associate with NSCP.

\section{Prenatal risk factors}

The prenatal risk factors of all fetuses and their mothers are given in table 2. By $\chi^{2}$ tests, it showed risk factors exposure in early pregnancy, vagina infected, incomplete placenta, rough placenta, abnormal amniotic fluid, illness history of mothers, and prenatal down's screening might associated with NSCP.

Of the 197 NSCL/P, 183 cases (92.89\%) had unilateral NSCL/P, and 14 cases $(7.11 \%)$ had bilateral NSCL/P. Table 3 showed the factors are associated with unilateral NSCL/P and which ones are associated with bilateral NSCL/P. By $\chi^{2}$ tests, all the factors with $\mathrm{p}$ value less than 0.05 were listed.

The results of the final simple logistic regression model were given in table 4. Risk factors exposure in early pregnancy, scarred uterus, vagina infected, assisted conception, incomplete placenta, placental roughness, abnormal amniotic fluid, not head presentation, folic acid intake $<3$ bottles during pre- and early pregnancy, mother's education is primary school or no schooling, and high risk of prenatal Down's screening were confirmed as the prenatal high risk factors on NSC/P.

\section{Discussion}

Orofacial clefts particularly cleft lip or/and cleft palate (CL/P) being a major public health problem, affecting thousands of children worldwide each year, with a frequency of 1 in 500 affecting more than 2.6 million people in China [7,9]. Many researches have focused on NSCL/P, especially with a target to distinguish the underlying genetic risk loci behind pathogenicity of $\mathrm{CL} / \mathrm{P}$, but as they all together accounts for only $20 \%-25 \%$ of NSCL/P heritability. 7 Most cases of CL/P are diagnosed in utero by ultrasound after 20 week's gestation, but some are undetected and only discovered at delivery and a small percentage of clefts are diagnosed during childhood [10,11]. So it is important to confirm the prenatal environmental and biological risk factors for auxiliary early diagnosis and etiology on NSCL/P.

The previous researches are still no consensus exists as to the cause of NSCL/P, researchers generally agree that genetic, nutritional, and environmental factors contribute to their formation [12].

Various reported environmental factors include smoking, alcohol use, some medications, folate deficiency, maternal obesity, maternal diseases such as diabetes and stress during pregnancy, chemical exposure, smoke from cooking indoors exposure [1,12-21]. But we found the risk factors exposure in early pregnancy had no association with NSCL/P when we took into account extensive prenatal factors, these factors include fever and other sicks, take medicines, radiation exposure, smoke, or drink wine, etc., however, each of these factors were seldom in pregnant couples for the popular practice of health care before pregnancy among the mothers of this study, so we took into account these risk factors together. It was different from some previous reports, this study showed maternal BMI, higher level of maternal education, family history of clefts, high or low parental age at time of childbirth, and maternal diseases such as diabetes were not associated with NSCL/P [1,22-24].

This study reflects only more than 3 months of daily intake of 0.4 $\mathrm{mg}$ folic acid before and during early pregnancy may help to reduce the risk of NSCL/P. However, there was a high heterogeneity between 
Table 1: The prenatal general characters of 192903 pregnant women and their fetuses without and with NSCPa

\begin{tabular}{|c|c|c|c|}
\hline General Characters & $\begin{array}{l}\text { No NSCL/P } \\
(n=192706)\end{array}$ & $N S C L / P(n=197)$ & P-value \\
\hline Age grades of mothers & & & 0.059 \\
\hline$<20$ years & 6939 (3.60\%) & $10(5.08 \%)$ & \\
\hline 20-35 years & $160812(83.45 \%)$ & $152(77.16 \%)$ & \\
\hline$\geq 35$ years & 24955 (12.95\%) & 35 (17.77\%) & \\
\hline $\begin{array}{l}\text { Years of mother's } \\
\text { education }\end{array}$ & & & 0.24 \\
\hline$\leq 12$ years & 118799 (61.65) & $130(65.99)$ & \\
\hline$>12$ years & 73907 (38.35) & $67(34.01)$ & \\
\hline Job of mothers & & & 0.89 \\
\hline $\begin{array}{l}\text { Temporary and } \\
\text { unemployed }\end{array}$ & $15836(8.22 \%)$ & $14(7.11 \%)$ & \\
\hline Housework & $41351(21.46 \%)$ & $43(21.83 \%)$ & \\
\hline Service staff & $9783(5.08 \%)$ & $10(5.08 \%)$ & \\
\hline Worker & 25129 (13.04\%) & $33(16.75 \%)$ & \\
\hline Enterprises and sale staff & $25721(13.35 \%)$ & 25 (12.69\%) & \\
\hline $\begin{array}{l}\text { Technical and public } \\
\text { service }\end{array}$ & $15254(7.92 \%)$ & $15(7.61 \%)$ & \\
\hline Others & $18152(9.42 \%)$ & 19 (9.64\%) & \\
\hline Unknown & $41480(21.53 \%)$ & $38(19.29 \%)$ & \\
\hline $\begin{array}{l}\text { Per capita household } \\
\text { income grades }\end{array}$ & & & 0.099 \\
\hline$>8000 \mathrm{RMB}$ & 28355 (14.71\%) & $40(20.30 \%)$ & \\
\hline$<2000 \mathrm{RMB}$ & 1585 (0.82\%) & $3(1.52 \%)$ & \\
\hline 2000-8000 RMB & 71902 (37.31\%) & $68(34.52 \%)$ & \\
\hline Unknown & 90864 (47.15\%) & $86(43.65 \%)$ & \\
\hline $\begin{array}{l}\text { Pre-pregnancy BMI } \\
\text { grades of mothers }\end{array}$ & & & 0.018 \\
\hline$<18.5$ & 29873 (15.50\%) & $20(10.15 \%)$ & \\
\hline $18.5-25$ & 103541 (53.73\%) & $101(51.27 \%)$ & \\
\hline$>25$ & $14130(7.33 \%)$ & $13(6.60 \%)$ & \\
\hline Unknown & $45162(23.44 \%)$ & $63(31.98 \%)$ & \\
\hline $\begin{array}{l}\text { Folic acid intake } \\
\text { during pre- and early } \\
\text { pregnancy }\end{array}$ & & & 0.031 \\
\hline$\geq 3$ bottles (months) & $47465(24.63 \%)$ & $35(17.77 \%)$ & \\
\hline$<3$ bottles (months) & 145241 (75.37\%) & $162(82.23 \%)$ & \\
\hline Gender of newborns & & & 0.47 \\
\hline Female & 91551 (47.51\%) & 85 (43.15\%) & \\
\hline Male & 101155 (52.49\%) & 112 (56.85\%) & \\
\hline
\end{tabular}

${ }^{a} \mathrm{NSCL} / \mathrm{P}$ is non-syndromic cleft lip or/and palate.

${ }^{\mathrm{b}} \mathrm{BMI}$ is body mass index.

'There are 31 tablets per bottle, and $0.4 \mathrm{mg}$ folic acid per tablet, the recommended daily intake is one tablet in 3 months before pregnancy and in first 3 months of pregnancy for every pregnant woman. the previous studies on the role of folate in the etiology of CL/P, such as population characteristics, variation in timing of exposure and supplement types, and publication bias. A previous study also showed low consumption of folic acid was found to be a risk factor of CL/P [22]. A review has reported that high-dose folic acid probably has a role in prevention of recurrence of isolated CL/P in high-risk individuals, but not cleft palate [25]. Another review has reported that mandatory folic acid fortification of wheat and/or maize flour may have beneficial effects on non-syndromic CL/P [26]. A recent meta-analysis also has shown that the risk of non-syndromic orofacial clefts was reduced among pregnant women with folic acid-containing supplements during the etiologically relevant period [27]. In Zhongshan of China, every pregnant woman is recommended daily intake of $0.4 \mathrm{mg}$ folic acid in 3 months before pregnancy and in first 3 months of pregnancy. This study also showed that less than 3 months of daily intake of 0.4 $\mathrm{mg}$ folic acid during pre- and early pregnancy was associated with the development of NSCL/P.

This study revealed that vagina infected fungi, bacteria, trichomonad, or gonorrhea as a total may increase the risk of NSC/LP. A previous report has shown maternal self-reported genital tract infections were associated with $\mathrm{CL} / \mathrm{P}$, but the strength of that conclusion was limited [28]. Meanwhile, in our study, the number of vagina infected (only 6 of 197 NSCL/P) was small and the occurrence of infected timing couldn't be determined in early pregnancy, so further study is still needed to confirm the association between vagina infected and NSCL/P.

We found assisted conception was associated with NSCL/P. Fauque $\mathrm{P}$, et al. have reported a moderately increased risk of defects (i.e. CL/P, etc. the 15 relevant subgroups of malformations) subsisted after IVF in a large study [29]. A meta-Analysis has reported that the IVF/ ICSI singleton pregnancies were significantly associated with high birth prevalence of congenital malformations (included CL/P), but it remains uncertain whether detected differences represent true or methodological differences [30]. However, this study only had a small number of assisted conception pregnancies (100 of 192706 no NSCL/P vs. 1 of $197 \mathrm{NSCL} / \mathrm{P})$, so the strength was limited.

We found several new prenatal factors increased the risk of the development of NSCL/P, they were incomplete placenta or rough surface placenta, abnormal amniotic fluid, and preterm or post-term delivery of newborns. Similar to the report, we also found low birth weight of newborns was associated with NSCL/P [24]. According to the results of this study, placental barrier may play a key role in the effect of environmental factor on NSCL/P, and a well status of placenta decreases the adverse effects of prenatal risk factors exposure. Meanwhile, maybe there are common risk factors between NSCL/P and preterm and low birth weight.

There are, however, several limitations. Firstly, we couldn't include all the previous reported risk factors of NSCL/P in this study, because we used the existing health care record databases to analyze. Secondly, although there was a large number in this retrospect cohort, but the number of NSCL/P was small (197 NSCL/P vs. 192706 no NSCL/P). Several risk factors showed in this study are needed further study to confirm.

\section{Conclusion}

Vagina infected, assisted conception, and insufficiency folic acid intake before and during early pregnancy, low birth weight of newborns were associated with a higher risk of the development of NSCL/P, which similar to previous studies. Our study adds several new prenatal risk factors of NSCL/P, includes incomplete placenta or rough surface placenta, abnormal amniotic fluid, preterm delivery

Citation: Li B, Xiao XH, Chen A, Li A, Lin HF, et al. (2021) The Prenatal High Risk Factors in Non-Syndromic Cleft Lip or/and Palate Fetuses:

A Cohort Study Based on Maternal Health Care Records of a Population. J Clin Case Stu 6(3): dx.doi.org/10.16966/2471-4925.229 
Table 2: The prenatal risk factors of 192903 pregnant women and their fetuses without and with NSCPa

\begin{tabular}{|c|c|c|c|}
\hline Prenatal Risk Factors & No NSCL/P ( $n=192706)$ & NSCL/P (n=197) & P-value \\
\hline Risk factors exposure in early pregnancy ${ }^{b}$ & $5733(2.97 \%)$ & $14(7.11 \%)$ & 0.0014 \\
\hline Assisted conception & $100(0.05 \%)$ & $1(0.51 \%)$ & 0.22 \\
\hline Scarred uterus & $20930(10.86 \%)$ & $27(13.71 \%)$ & 0.24 \\
\hline Gestational diabetes mellitus & $15773(8.19 \%)$ & $15(7.61 \%)$ & 0.87 \\
\hline Hypertensive disorder & $5068(2.63 \%)$ & $8(4.06 \%)$ & 0.3 \\
\hline Thalassemia carrier & $3869(2.01 \%)$ & $7(3.55 \%)$ & 0.2 \\
\hline Anemia & $7650(3.97 \%)$ & $10(5.08 \%)$ & 0.54 \\
\hline Thyroid dysfunction or abnormalities & $1372(0.71 \%)$ & $3(1.52 \%)$ & 0.35 \\
\hline Vagina infected ${ }^{c}$ & $1855(0.96 \%)$ & $6(3.05 \%)$ & 0.0087 \\
\hline $\mathrm{G}^{\mathrm{P} P D^{\mathrm{d}}}$ & $996(0.52 \%)$ & $3(1.52 \%)$ & 0.14 \\
\hline Incomplete placenta or rough surface placenta & $6567(3.41)$ & $46(23.35)$ & 0 \\
\hline Torsion of umbilical cord & $1994(1.03 \%)$ & $2(1.02 \%)$ & 1 \\
\hline Umbilical cord around neck & $52535(27.26 \%)$ & $46(23.35 \%)$ & 0.25 \\
\hline Abnormal amniotic fluide & $32258(16.74 \%)$ & $76(38.58 \%)$ & 0 \\
\hline Not head presentation & $15092(7.83 \%)$ & $24(12.18 \%)$ & 0.032 \\
\hline Low birth weight of newborns & $8146(4.23)$ & $78(39.59)$ & 0 \\
\hline Illness history of mothers & & & 0 \\
\hline No & $187173(97.13 \%)$ & 182 (92.39\%) & \\
\hline Yes & $3022(1.57 \%)$ & $4(2.03 \%)$ & \\
\hline Unknown & $2511(1.30 \%)$ & $11(5.58 \%)$ & \\
\hline Prenatal Down's screening & & & 0.031 \\
\hline Low risk & 120237 (62.39\%) & 105 (53.30\%) & \\
\hline High risk & $67866(35.22 \%)$ & $86(43.65 \%)$ & \\
\hline Unknown & $4603(2.39 \%)$ & $6(3.05 \%)$ & \\
\hline Liver function test $^{\dagger}$ & & & 0.16 \\
\hline Normal & $60148(31.21 \%)$ & $49(24.87 \%)$ & \\
\hline Abnormal & $859(0.45 \%)$ & $1(0.51 \%)$ & \\
\hline Unknown & $131699(68.34 \%)$ & $147(74.62 \%)$ & \\
\hline Renal function test ${ }^{g}$ & & & 0.14 \\
\hline Normal & $58562(30.39 \%)$ & $47(23.86 \%)$ & \\
\hline Abnormal & $980(0.51 \%)$ & $1(0.51 \%)$ & \\
\hline Unknown & $133164(69.10 \%)$ & $149(75.63 \%)$ & \\
\hline Urine occult blood & & & 0.95 \\
\hline Negative & 14811 (7.69\%) & $15(7.61 \%)$ & \\
\hline Positive & $1360(0.71 \%)$ & $1(0.51 \%)$ & \\
\hline Unknown & $176535(91.61 \%)$ & $181(91.88 \%)$ & \\
\hline Hepatitis B surface antigen & & & 0.13 \\
\hline Negative & $154760(80.31 \%)$ & $150(76.14 \%)$ & \\
\hline Positive & $12132(6.30 \%)$ & $11(5.58 \%)$ & \\
\hline Unknown & $25814(13.40 \%)$ & $36(18.27 \%)$ & \\
\hline Syphilis test & & & 0.15 \\
\hline Negative & $165494(85.88 \%)$ & $160(81.22 \%)$ & \\
\hline Positive & $453(0.24 \%)$ & $1(0.51 \%)$ & \\
\hline Unknown & 26759 (13.89\%) & $36(18.27 \%)$ & \\
\hline Delivery period of newborns & & & 0 \\
\hline Preterm delivery & $9268(4.81)$ & $74(37.56)$ & \\
\hline Term delivery & $183002(94.96)$ & $121(61.42)$ & \\
\hline Post-term delivery & $436(0.23)$ & $2(1.02)$ & \\
\hline
\end{tabular}

${ }^{a} \mathrm{NSCL} / \mathrm{P}$ is non-syndromic cleft lip or/and palate.

${ }^{\text {b}}$ Risk factors include fever, other sickness, take medicines, radiation exposure, smoke, or drink wine, etc.

'Vagina infected fungi, bacteria, trichomonad, or gonorrhea.

${ }^{\mathrm{d}} \mathrm{G} 6 \mathrm{PD}$ is glucose-6-phosphate dehydrogenase deficiency.

eAbnormal amniotic fluid includes Polyhydramnios, Oligohydramnios, abnormal smell or colour, etc.

fLiver function test includes serum alanine aminotransferase, serum aspartate aminotransferase, albumin, total

bilirubin, and conjugated bilirubin.

${ }^{8}$ Renal function test includes serum creatinine and urea nitrogen.

Citation: Li B, Xiao XH, Chen A, Li A, Lin HF, et al. (2021) The Prenatal High Risk Factors in Non-Syndromic Cleft Lip or/and Palate Fetuses: 
Table 3: The prenatal risk factors of 192903 pregnant women and their fetuses without and with unilateral or bilateral NSCPa

\begin{tabular}{|c|c|c|c|c|}
\hline \multirow{2}{*}{ Prenatal Risk Factors } & No NSCL/P & Unilateral NSCL/P & Bilateral NSCL/P & \multirow{2}{*}{ P-value } \\
\hline & $(n=192706)$ & $(n=183)$ & $(n=14)$ & \\
\hline Risk factors exposure in early pregnancy ${ }^{b}$ & $5733(2.97)$ & $13(7.10)$ & $1(7.14)$ & 0.003 \\
\hline Assisted conception & $100(0.05)$ & $1(0.55)$ & $0(0.00)$ & 0.014 \\
\hline Hypertensive disorder & $5068(2.63)$ & $6(3.28)$ & $2(14.29)$ & 0.021 \\
\hline Vagina infected ${ }^{c}$ & 1855(0.96) & $6(3.28)$ & $0(0.00)$ & 0.0055 \\
\hline $\mathrm{G} \mathrm{PD}^{\mathrm{d}}$ & $996(0.52)$ & $2(1.09)$ & $1(7.14)$ & 0.0014 \\
\hline Incomplete placenta or rough surface placenta & $6567(3.41)$ & $40(21.86)$ & $6(42.86)$ & 0 \\
\hline Abnormal amniotic fluide & $32258(16.74)$ & $69(37.70)$ & $7(50.00)$ & 0 \\
\hline Low birth weight of newborns & $8146(4.23)$ & $71(38.80)$ & $7(50.00)$ & 0 \\
\hline Illness history of mothers & & & & 0 \\
\hline No & 187173(97.13) & $168(91.80)$ & $14(100.00)$ & \\
\hline Yes & $3022(1.57)$ & $4(2.19)$ & $0(0.00)$ & \\
\hline Unknown & $2511(1.30)$ & $11(6.01)$ & $0(0.00)$ & \\
\hline Prenatal Down's screening & & & & 0.025 \\
\hline Low risk & $120237(62.39)$ & $94(51.37)$ & $11(78.57)$ & \\
\hline High risk & $67866(35.22)$ & $83(45.36)$ & $3(21.43)$ & \\
\hline Unknown & $4603(2.39)$ & $6(3.28)$ & $0(0.00)$ & \\
\hline Delivery period of newborns & & & & 0 \\
\hline Preterm delivery & $9268(4.81)$ & $67(36.61)$ & $7(50.00)$ & \\
\hline Term delivery & $183002(94.96)$ & $114(62.30)$ & $7(50.00)$ & \\
\hline Post-term delivery & $436(0.23)$ & $2(1.09)$ & $0(0.00)$ & \\
\hline
\end{tabular}

${ }^{a} \mathrm{NSCL} / \mathrm{P}$ is non-syndromic cleft lip or/and palate.

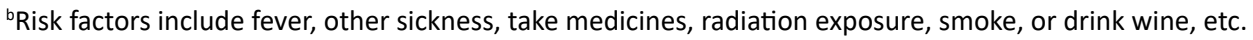

'Vagina infected fungi, bacteria, trichomonad, or gonorrhea.

${ }^{\mathrm{d}} \mathrm{G} 6 \mathrm{PD}$ is glucose-6-phosphate dehydrogenase deficiency.

eAbnormal amniotic fluid includes Polyhydramnios, Oligohydramnios, abnormal smell or colour, etc.

Table 4: The prenatal high risk factors on NSCL/Pa were discovered by logistic regression model.

\begin{tabular}{|c|c|c|c|c|c|}
\hline Prenatal Risk Factors & Estimate & Standard Error & Z-value & OR $(95 \% \mathrm{Cl})$ & P-value \\
\hline Vagina infected ${ }^{b}$ & 1.23 & 0.42 & 2.92 & $3.43(1.34,7.19)$ & 0.003 \\
\hline Assisted conception & 2.45 & 1.02 & 2.4 & $11.57(0.65,54.29)$ & 0.016 \\
\hline Incomplete placenta or rough surface placenta & 1.54 & 0.18 & 8.48 & $4.65(3.23,6.57)$ & 0 \\
\hline Abnormal amniotic fluid ${ }^{c}$ & 1.01 & 0.15 & 6.72 & $2.74(2.04,3.67)$ & 0 \\
\hline $\begin{array}{l}\text { Folic acid intake }<3 \text { bottles (moths) during pre- } \\
\text { and early pregnancy }{ }^{d}\end{array}$ & 0.45 & 0.19 & 2.39 & $1.57(1.10,2.30)$ & 0.017 \\
\hline Low birth weight of newborns & 1.69 & 0.23 & 7.22 & $5.44(3.41,8.54)$ & 0 \\
\hline \multicolumn{6}{|l|}{ Delivery period of newborns } \\
\hline Term delivery & & & & 1 & \\
\hline Preterm delivery & 1.19 & 0.24 & 5.02 & $3.29(2.07,5.24)$ & 0 \\
\hline Post-term delivery & 1.78 & 0.72 & 2.48 & $5.94(0.97,18.93)$ & 0.013 \\
\hline
\end{tabular}

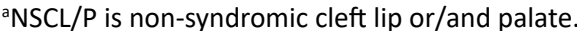

bVagina infected fungi, bacteria, trichomonad, or gonorrhea.

'Abnormal amniotic fluid includes polyhydramnios, oligohydramnios, abnormal smell or colour, etc.

dThere are 31 tablets per bottle, and $0.4 \mathrm{mg}$ folic acid per tablet, the recommended daily intake is one tablet in 3 months before pregnancy and in first

3 months of pregnancy for every pregnant woman.

Citation: Li B, Xiao XH, Chen A, Li A, Lin HF, et al. (2021) The Prenatal High Risk Factors in Non-Syndromic Cleft Lip or/and Palate Fetuses: 
or post-term delivery. This study strengthens the importance role of interaction between the placental barrier and various environmental factors on the development of NSCL/P.

\section{Acknowledgements}

We would like to thank the management team of health bureau of Zhongshan City for extracting the de-identified data from regional maternal and children health care information system.

\section{Authors's Contributors}

$\mathrm{BL}, \mathrm{XH} \mathrm{X}$, and FH L conceptualised and designed the study, reviewed and revised the manuscript. BL conducted the statistical analysis, drafted the initial manuscript. AC contributed to acquire and sort the data. YL, HF L, and HZ L contributed to sort the data. All authors read and approved the final manuscript.

\section{Funding}

Funded by grants from the Ministry of Science and Technology of the People's Republic of China (project ID 2018YFC1002600, 2018YFC1002604, and 2018YFC1002601).

\section{Ethics Approval and Consent to Participate}

This study was approved by the ethical review board of Guangdong Women and Children Hospital, approval number: 201801023 (decision 2018-07-18). The authors declare that the experiments comply with the relevant guidelines and regulations of ethical review of biomedical research involving human beings issued by Health and Family Planning Commission of the people's Republic of China in 2016. We used the de-identified historical health record data belong to information centre of health bureau of Zhongshan city, and informed consent was waived by the ethical review board of Guangdong Women and Children Hospital.

\section{References}

1. Vyas T, Gupta P, Kumar S, Gupta R, Gupta T, et al. (2020) Cleft of lip and palate: A review. J Family Med Prim Care 9: 2621-2625.

2. Sankar SG (2011) Text book of orthodontics. $1^{\text {st }}$ ed. Paras Medical Publication.

3. Allan E, Windson LJ, Stone C (2014) Cleft lip and palate: Etiology, epidemiology, prevention and intervention strategies. Anat Physiol 4: 1-6.

4. Berkowitz S (2006) Cleft lip and palate diagnosis and management. $2^{\text {nd }}$ ed. Springer.

5. Lakhanpal M, Gupta N, Rao NC, Vashisth S (2014) Genetics of Cleft Lip and Palate-Is it still patchy? JSM Dent 2: 1030.

6. Kohli SS, Kohli VS (2012) A comprehensive review of the genetic basis of cleft lip and palate. J Oral Maxillofac Pathol 16: 64-72.

7. Saleem K, Zaib T, Sun W, Fu S (2019) Assessment of candidate genes and genetic heterogeneity in human non syndromic orofacial clefts specifically non syndromic cleft lip with or without palate. Heliyon 5: e03019.

8. Lou S, Ma L, Kan S, Yu X, Wang Y, et al. (2020) Association Study of Genetic Variants in Autophagy Pathway and Risk of Non-syndromic Cleft Lip With or Without Cleft Palate. Front Cell Dev Biol 8: 576.

9. Dixon MJ, Marazita ML, Beaty TH, Murray JC (2011) Cleft lip and palate: understanding genetic and environmental influences. Nat Rev Genet 12: 167-178.
10. Lewis CW, Jacob LS, Lehmann CU (2017) The primary care pediatrician and the care of children with cleft lip and/or cleft palate. Pediatrics 139: e20170628.

11. Dam ET, Der Heijden PV, Korsten-Meijer AGW, Goorhuis-Brouwer SM, Van Der Laan BFAM (2013) Age of diagnosis and evaluation of consequences of submucous cleft palate. Int J Pediatr Otorhinolaryngol 77: 1019-24.

12. Alois $\mathrm{Cl}$, Ruotolo (2020) An overview of cleft lip and palate. JAAPA 33: 17-20.

13. Centers for Disease Control and Prevention (2020) Facts about cleft lip and cleft palate.

14. Shkoukani MA, Chen M, Vong A (2013) Cleft lip-a comprehensive review. Front Pediatr 1: 53.

15. Hong $Y, X u X$, Lian F, Chen R (2021) Environmental Risk Factors for Nonsyndromic Cleft Lip and/or Cleft Palate in Xinjiang Province, China: A Multiethnic Study. Cleft Palate Craniofac J 58: 489-496.

16. Li H, Luo M, Luo J, Zheng J, Zeng R, et al. (2016) A discriminant analysis prediction model of non-syndromic cleft lip with or without cleft palate based on risk factors. BMC Pregnancy Childbirth 16: 368.

17. Martelli DRB, Coletta RD, Oliveira EA, Swerts MSO, Rodrigues LAM, et al. (2015) Association between maternal smoking, gender, and cleft lip and palate. Braz J Otorhinolaryngol 81: 514-519.

18. Auslander A, McKean-Cowdin R, Brindopke F, Sylvester B, DiBona M (2020) The role of smoke from cooking indoors over an open flame and parental smoking on the risk of cleft lip and palate: A casecontrol study in 7 low-resource countries. J Glob Health 10: 020410.

19. Kapos FP, White LA, Schmidt KA, Hawes SE, Starr JR (2021) Risk of non-syndromic orofacial clefts by maternal rural-urban residence and race/ethnicity: A population-based case-control study in Washington State 1989-2014. Paediatr Perinat Epidemiol 35: 292301.

20. Zarante I, López MA, Caro A, García-Reyes JC, Ospina JC (2009) Impact and risk factors of craniofacial malformations in a Colombian population. Int J Pediatr Otorhinolaryngol 73: 1434-1437.

21. Kurita H, Motoki N, Inaba Y, Misawa Y, Ohira S, et al. (2020) Maternal alcohol consumption and risk of offspring with congenital malformation: the Japan Environment and Children's Study. Pediatr Res.

22. Jamilian A, Sarkarat F, Jafari M, Neshandar M, Amini E, et al. Family history and risk factors for cleft lip and palate patients and their associated anomalies. Stomatologija 19: 78-83.

23. Lin Y, Shu S, Tang S (2014) A case-control study of environmental exposures for nonsyndromic cleft of the lip and/or palate in eastern Guangdong, China. Int J Pediatr Otorhinolaryngol 78: 544-550.

24. Chowchuen B, Surakunprapha $P$, Winaikosol K, Punyavong $P$, Kiatchoosakun P, et al. (2021) Birth Prevalence and Risk Factors Associated With CL/P in Thailand. Cleft Palate Craniofac J 58: 557566.

25. Jayarajan R, Natarajan A, Nagamuttu R (2019) Efficacy of Periconceptional High-Dose Folic Acid in Isolated Orofacial Cleft Prevention: A Systematic Review. Indian J Plast Surg 52: 153-159.

26. Millacura N, Pardo R, Cifuentes L, Suazo J (2017) Effects of folic acid fortification on orofacial clefts prevalence: a meta-analysis. Public Health Nutr 20: 2260-2268.

27. Zhou Y, Sinnathamby V, Yu Y, Sikora L, Johnson Cy, et al. (2020) Folate intake, markers of folate status and oral clefts: An updated set of systematic reviews and meta-analyses. Birth Defects Res 112: 16991719. 
28. Carter TC, Olney RS, Mitchell AA, Romitti PA, Bell EM, et al. (2011) Maternal self-reported genital tract infections during pregnancy and the risk of selected birth defects. Birth Defects Res A Clin Mol Teratol 91: 108-116.

29. Fauque P, De Mouzon J, Devaux A, Epelboin S, Gervoise-Boyer MJ, et al. (2021) Do in vitro fertilization, intrauterine insemination or female infertility impact the risk of congenital anomalies in singletons? A longitudinal national French study. Hum Reprod 36: 808-816.

30. Chen L, Yang T, Zheng Z, Yu H, Wang H, et al. (2018) Birth prevalence of congenital malformations in singleton pregnancies resulting from in vitro fertilization/intracytoplasmic sperm injection worldwide: a systematic review and meta-analysis. Arch Gynecol Obstet 297: $1115-1130$. 